\title{
Innovation Throw and Catch Handball by Frisbee at Students of Riau Islamic University
}

\author{
"Leni Apriani ${ }^{1}$ Joni Alpen ${ }^{2}$ \\ ${ }^{1,2}$ Universitas Islam Riau \\ ${ }^{*}$ Corresponding author. Email: leniapriani@edu.uir.ac.id

\begin{abstract}
The study aims to obtain empirical data on the success rate of handball catch through Frisbee games in college students. The Class Action Research Method (PTK) used is class action research conducted to improve the quality of learning practices in the classroom. PTK focuses on the school or teaching and learning process that occurs at the school, not on classroom input. The sample was studied by 120 students. The result of this study is that the application of modifications can improve throwing and better catch. The conclusion is that through frisbee games, the success rate of throwing and catching increases.
\end{abstract}

Keywords: Frisbee games, HandBall, Innovation, Throw and catch.

\section{INTRODUCTION}

The education provided aims to form an intelligent and critical human being to become a qualified human being. This can be realized through comprehensive education, including education that trains analytical to creative ways of thinking. Physical education can provide more benefits than just physical health in exercising. Physical education can also play a role for its implementer and have a change impact [1]. Physical education is a learning process through a physical activity designed to improve physical fitness, develop motor skills, knowledge and behaviors of healthy and active living, sportsmanship, and emotional intelligence. Schools and specifically physical education subjects are considered to have a significant role in increasing physical activity that benefits their physical fitness [2].

A healthy learning environment helps the growth and development of cognitive, affective, and psychomotor aspects. Doing enough physical activity will positively impact mental health and reduce the symptoms of stress [3]. Physical activity makes the body better in terms of physiological health, psychological well-being, and cognitive performance may also improve motor performance and motor learning processes [4]. Sports is one of the activities that can unite all elements of society regardless of ethnicity, race, or religion. No one in this world doesn't like sports, from ordinary people to officials. This happens because one goal is to create a strong body and a healthy soul.

Sports are known as individuals, and teams are even considered opponents [5]. One of the sports played by a team is Handball. Handball is an attractive game that requires physical ability and good anthropometric support. Handball combines fast attack and highintensity training interspersed with moderate and even low exercise [6]. Movement in Handball requires that the player has excellent physical ability and supportive anthropometric abilities. The rules of the modern handball game were established in the 1920s and included the Sport contested at the Olympics [7]. Handballs have developed and been played by men and women worldwide, especially in Europe, which is already popular [8]. Movement in handball games consists of running, jumping and throwing, catching, blocking, and pushing between players. In addition to technical and tactical skills, one of the critical skills required to succeed in a handball team is throwing. To achieve the goals of physical education, handball games must pay attention to suitable learning methods so that students can understand, understand, and feel happy when participating in handball learning. In addition, a teacher must also apply the right approach, using modified facilities and equipment, the complexity of skills, game objectives, and the learning atmosphere. A handball team game is done by throwing and catching the 
ball using one or both hands to put the ball as much as possible into the opponent's goal.

The Sport of Handball is indoor. Handball is a game played by two teams of seven people each. Each team tries to put the ball into the opponent's goal and prevent the opposing team from entering the ball. The ball can be given by hand or by dribbling several times to the floor without touching both hands simultaneously. Some rules were changed to make the game more entertaining and can be covered by many media to the broader community and inform the audience that the game is currently more active [9].

Playing Handball can be done in various forms, one of which is playing throw and catch. Learning strategies play an essential role in throwing and capturing learning because learning goals can also be achieved optimally in the right learning strategy. The learning process is vital and must be understood by every physical education teacher. How the teaching staff determines the goals to achieve the expected results, the material under the course so that the learning process runs in an orderly and smooth manner, it is all the responsibility and duty of the teaching staff, In addition, the teacher's task is to prepare mental and healthy life choices to develop the character into adulthood and provide the amplest opportunity for children to move and develop their skills [10].

Handball is a combination of football and basketball. Handball games are almost entirely played using hands and are assisted by other body parts except the feet. Only the goalkeeper uses his feet. The game lasts $2 \times 35$ minutes with a 10-minute break. Handball is a team game done by throwing and catching the ball using one or both hands to put as many balls into the opponent's goal. The handball game consists of several essential techniques: warm-up, dribbling, passing, attacking shooting, drills, defensive positioning, and short rest exercises. But in the game, only three basic techniques are most often used, including; (1) Technique, dribbling is the player's attempt to bring the ball close to the opponent's defensive area by bouncing the ball to the floor, (2) passing technique that is an attempt to give the ball to a friend using one or two hands.

Play can be done in various forms, one of which is playing throwing and catching. Throwing is one of the basic movements to move objects away from the body using one or two hands. In contrast, capture is an essential manipulative motion skill to stop the speed of an object using the hand. Student handball games must be able to anticipate the movements that come to be performed later [11].

Learning handball games, in addition to cognitive and psychomotor aspects, students also learn affective aspects related to behavior and attitude. In terms of effectiveness, many goals and benefits are expected to be achieved by participating in handball learning, including sportsmanship, having a sense of responsibility, desire to work together, being quick to make decisions, respecting opponents playing, and so on. At. The game included in the invasion game is the frisbee game. A frisbee game is a game of throwing and catching tools such as plates (flat) made so that they can float in the air with a balanced slide that pays attention to the aerodynamic principles of the instrument. The game contains movements and rules of sports in groups such as basketball and netball [12]. The implementation of learning must be many variations of tasks to cause interest and provide satisfaction in practicing it [13]. The main object of the frisbee game is a tool made of plastic in the form of a flat-convex disc. The shape is aerodynamically designed, which means the agency can float in balance in the air and achieve optimal distances. Flat-shaped tools can penetrate the atmosphere better than other forms, such as boards, hazardous shards, cards. We can throw and penetrate the air quickly, but it isn't easy to aim. However, there is no precise method to develop how to throw in the game [14].

In essence, this frisbee game belongs to the group of interception passing games. Because the competition aims to produce a score in the opponent's area, bypassing the frisbee throwing skill to be directed and captured by one team player, while the opposing team's players attempt to block attempts to score. The frisbee game is still not famous among the public because this game is rarely played by schools and the public. A frisbee is needed to throw the perfect catch to put the ball into the goal in the game

The movement skills learned during handball lessons are catching, throwing/ passing, dribbling, and shooting the ball. In playing conditions, throwing and catching activities in frisbee games are very fun because the aerodynamic movement of the frisbee looks attractive to students. If students have started to feel interested, students can move actively and enjoy following the physical education learning process. In playing conditions, throwing and catching activities in frisbee games are very fun because the aerodynamic movement of the frisbee looks attractive to students. If students have started to feel interested, students can move actively and enjoy following the physical education learning process.

Based on observations during the learning process of handball courses, some students are less able to practice playing by throwing and catching the ball. Students look very stiff when throwing and catching; students still need help directions from teachers when throwing and catching. Students look awkward and stiff when throwing and catching; students cannot maintain balance after throwing and catching movements. In addition, children seem to hesitate to throw or catch the ball and lack 
confidence in their abilities, so the motivation of the teaching staff is very influential on the student himself. Therefore, it is necessary to improve some other skills to get better at playing handball [15]. The goal of this study was to find out the success rate in doing handball capture through Frisbee play.

\section{METHODS}

Classroom Action Research (PTK), according to the section chart, can go through stages, namely (1) planning, (2) implementation, (3) observation, and (4) reflection. Under the issues raised, this type of research is classroom action research, which aims to improve the quality of classroom learning and problem-solving faced in the learning process. PTK's goal is to strengthen and enhance classroom learning practices continuously. The sampling technique in this study is total sampling. Total sampling is where the number of samples is equal to the population. This study sample is all students of Penjaskesrek, as many as 120 students. Data collected by researchers was analyzed to find out the target of learning achievement using the formula.

Value $=\frac{\text { The Total of Scores Obtained }}{\text { Maximum Total of Scores }}$

The formulas used to determine classical completeness are as follows:

$\mathrm{P}=\frac{F}{N} \times 100 \%$

Information:

$\mathrm{P}=$ percentage of classical completeness

$\mathrm{F}=$ Frequency of students completing

$\mathrm{N}=$ Maximum score

\section{RESULTS}

Data obtained in the form of student learning assessment results or student abilities. The ability of students assessed here is the power of basic techniques to throw Handball. Then the student's ability data is presented in the form of a table. The results of the presentation of the table are outlined as described in cycle I or after the application of the frisbee game; the average value of handball catching skills through frisbee games in sports team students can be seen in the following table.

Table 1. Throw and catch analysis

\begin{tabular}{|c|c|c|c|c|}
\hline No & Interval & Category & Total & Percentage \\
\hline 1 & $\geq 84$ & Excellent & 12 & $10 \%$ \\
\hline 2 & $69 \leq 83$ & Good & 19 & $15,83 \%$ \\
\hline 3 & $55 \leq 68$ & Fair & 28 & $23,33 \%$ \\
\hline 4 & $39 \leq 54$ & Enough & 38 & $31,66 \%$ \\
\hline 5 & $<38$ & Very Enough & 23 & $19,16 \%$ \\
\hline \multicolumn{3}{|c|}{ Total } & 120 & \multirow{3}{*}{$100 \%$} \\
\hline \multicolumn{3}{|c|}{ Average } & 57 & \\
\hline \multicolumn{3}{|c|}{ Category } & Fair & \\
\hline
\end{tabular}

There is an average value of 57 categories "Enough" in cycle I, then in cycle II, there is an average value of 71 types "Fair." Lecturer activity in process II affects the activeness of students in the following learning. Where it is known that the average value of student activity in cycle II is $88.6 \%$ so that overall student activity in cycle II is carried out well. The essential motion ability of handball throwing can improve the knowledge and skills of the lecturer in understanding learning outcomes and organizing the learning process well, especially in the teaching materials of sports theory and practice in the field. All learning methods and classroom management techniques applied during the handball learning process in lectures can enrich prospective teachers' cognitive and psychomotor abilities of physical education and health sports in understanding and implementing learning methods, managing the learning process, and measuring learning outcomes. Giving modifications makes students feel happy, highly motivated, and comfortable [16].

\section{DISCUSSION}

Handball games are included in big ball sports. Handball games are more accurately referred to as a combination game of basketball and soccer games because the basic techniques resemble the basic methods of basketball games. To score goals, offensive players (6 players and one goalkeeper) attempt to establish optimal positions for players who throw in short, fast motions, make significant directional changes (with and without the ball), one-on-one action against defenders, and pass the ball using different offensive tactics [17]. In the process of teaching and learning handball, players are equipped with good basic techniques. Handball is a highly dynamic, disciplined sport, where short actions do not last longer than 10-20 seconds [18]. Players who have good basic technique tend to be able to play Handball well too. Playing Handball can be done in various forms, one of which is play throwing and catching.

Handball is an intermittent high-intensity body contact in team sports, characterized by sprinting, jumping, throwing, hitting, blocking, and pushing [19]. I studied through the appearance of basic handball movements. The ability to throw a ball can be used as the forerunner to developing other fundamental movement skills; for example, passing or shooting a ball is the development of throwing motion. Ball throwing speed is evaluated in a handball courtroom using two types of throws: a standing throw from a distance of $7 \mathrm{~m}$ and a three-step running throw. Standard Handball was used for all tests. Standing throws require participants to throw the ball as quickly as possible through a common goal using their dominant hand [20]. A good throwing ability from a player will have a significant impact on the team in winning a match. The throwing ability of players is 
needed, including the ability to throw strength/speed and throwing accuracy in scoring goals. In learning Handball, there are modifications made by the teaching staff due to facilities and infrastructure factors. Students who are not familiar with Handball and Handball are only taught at the university level.

It is interesting to see that each student is interested in learning Handball through the game of frisbee. This is a challenge for the teaching staff so that there are no more students whose throwing and catching skills are not good.

Learning media and physical education modification are some of the supporting factors in the success of the teaching and learning process on campus. Still, the lack of availability of facilities and infrastructure dramatically affects the results of the learning process. Movement in handball games consists of running, jumping and throwing, catching, blocking, and pushing between players, in addition to technical and tactical skills. Then it is also relevant to the results of research that have been carried out by [21]. This study compared the effect of high-intensity interval training (HIT) versus particular game-based handball training (HBT) on Handball. The handball game that students learn in lectures should be physical activity and be able to improve basic handball movement skills that are integrated with intellectual development, health, and community productivity.

\section{CONCLUSION}

Based on the analysis of data in this study obtained from the analysis of learning skills and outcomes. The ability to throw Handball through a frisbee game in a student class is the average student's ability in cycle I, the ability to throw handball students with the category Enough. In contrast, in cycle II the ability of students is a good category. Based on the data and information processing results above, it can be concluded that students achieve successful handball catching skills. The achievement of such success is supported by several things including, that the frisbee game is preferred by students. This is evident when students take the skills to learn ball throwing skills.

\section{REFERENCES}

[1] V. Balan, G. Marinescu, L. Ticala, and M. Shao, "Physical Education-Longlife Learning Factor," Procedia - Soc. Behav. Sci., vol. 46, pp. 1328-1332, 2012.

[2] S. Guijarro-Romero, J. Viciana, C. Casado-Robles, and D. Mayorga-Vega, "Does a physical educationbased fitness program benefit everyone regardless of the student's physical fitness profile? A clusterrandomized controlled trial," J. Phys. Educ. Sport, vol. 20, no. 3, pp. 1550-1560, 2020.
[3] X. Zhan, C. C. T. Clark, R. Bao, M. Duncan, J. T Hong, and S. T. Chen, "Association between physical education classes and physical activity among 187,386 adolescents aged 13-17 years from 50 low- and middle-income countries," J. Pediatr. (Rio. J)., no. xx, 2021.

[4] L. Hübner and C. Voelcker-Rehage, "Does physical activity benefit motor performance and learning of upper extremity tasks in older adults? - A systematic review," Eur. Rev. Aging Phys. Act., vol. 14, no. 1, pp. 1-19, 2017.

[5] I. Mujika, "Winning the BIG medals," Int. J. Sports Physiol. Perform., vol. 12, no. 3, pp. 273-274, 2017.

[6] A. Muñoz, Á. López-Samanes, R. Domínguez, V. Moreno-Pérez, A. J. Sánchez-Oliver, and J. Del Coso, "Use of sports supplements in competitive handball players: Sex and competitive level differences," Nutrients, vol. 12, no. 11, pp. 1-14, 2020.

[7] G. Raiola, P. L. Invernizzi, R. Scurati, and S. Fattore, "The educational value of the rules in handball," J. Hum. Sports Exerc., vol. 15, no. 4, pp. S1214-S1223, 2020.

[8] H. Wagner, P. Fuchs, A. Fusco, P. Fuchs, J. W. Bell, and S. P. von Duvillard, "Physical performance in elite Male and female team-handball players," Int. J. Sports Physiol. Perform., vol. 14, no. 1, pp. 60 67, 2019.

[9] Z. Marczinka and A. Gál, "The chain reaction between the media and Sport. The impact of rule changes in Handball," Phys. Cult. Sport. Stud. Res., vol. 80, no. 1, pp. 39-47, 2018.

[10] M. F. Ali, S. Kundra, M. A. Alam, and M. Alam, "Investigating stress, anxiety, social support and sex satisfaction on physical education and sports teachers during the COVID-19 pandemic," Heliyon, vol. 7, no. 8, p. e07860, 2021.

[11] F. Loffing and N. Hagemann, "Skill differences in visual anticipation of type of throw in teamhandball penalties," Psychol. Sports Exerc., vol. 15, no. 3, pp. 260-267, 2014.

[12] A. A. T. S. Canlan, C. R. O. K. Ean, and B. R. J. H. Umphries, "Physiological and Fatigue Responses Associated With Male and Mixed-Gender Ultimate Frisbee Game Play," J. Strength Cond. Res., vol. 29, no. 9, pp. 2600-2607, 2015.

[13] Á. Abós, L. García-González, A. Aibar, and J. Sevil-Serrano, "Towards a better understanding of the role of perceived task variety in Physical Education: A self-determination theory approach,' 
Psychol. Sports Exerc, vol. 56, no. May 2021.

[14] S. D. Skejø et al., "Quantifying throwing load in handball: a method for measuring the number of throws," Sport. Biomech., 2021.

[15] F. Gimeno, R. Castillo, and C. Marcen, "Psychological Skills Evolution During a Sports Season of Coaches of Women's Handball Teams," Procedia - Soc. Behav. Sci., vol. 82, pp. 727-729, 2013.

[16] A. Haris and M. I. Ghazali, "Development of mutual adaptation model PE teaching in Indonesia," Int. J. Yoga, Physiother. Phys. Educ. Int., vol. 3, no. 4, pp. 74-80, 2018.

[17] H. Wagner, T. Finkenzeller, S. Würth, and S. P. Von Duvillard, "Individual and team performance in team-handball: A review," J. Sport. Sci. Med., vol. 13, no. 4, pp. 808-816, 2014.

[18] M. Spieszny and M. Zubik, "Modification of Strength Training Programs in Handball Players and its Influence on Power during the Competitive Period," J. Hum. Kinect., vol. 63, no. 1, pp. 149160, 2018.

[19] S. P. J. Matthys et al., "A multidisciplinary identification model for youth handball," Eur. J. Sports Sci., vol. 11, no. 5, pp. 355-363, 2011.

[20] A. Chaouachi, M. Brughelli, G. Levin, N. B. B. Boudhina, J. Cronin, and K. Chamari, "Anthropometric, physiological and performance characteristics of elite team-handball players," J. Sports Sci., vol. 27, no. 2, pp. 151-157, 2009.

[21] M. Buchheit, P. B. Laursen, J. Kuhnle, D. Ruch, C. Renaud, and S. Ahmaidi, "Game-based training in young elite handball players.," Int. J. Sports Med., vol. 30, no. 4, pp. 251-258, 2009. 